\title{
Impact of Mobile Endoscopy Unit for Rendering Gastrointestinal Endoscopy Services at Two Community Health Centers in Western India
}

\author{
Amit Maydeo ${ }^{1}$ Shivaji Thakare ${ }^{1}$ Amol Vadgaonkar ${ }^{1}$ Gaurav Patil ${ }^{1}$ Ankit Dalal ${ }^{1}$ Nagesh Kamat ${ }^{1}$ \\ Sehajad Vora ${ }^{1}$ \\ ${ }^{1}$ Baldota Institute of Digestive Sciences, Gleneagles Global Hospital, \\ Mumbai, Maharashtra, India \\ Address for correspondence Gaurav Patil, MBBS, DNB (Medicine), \\ DNB (Gastro), Baldota Institute of Digestive Sciences, Gleneagles \\ J Digest Endosc 2021;12:190-195. \\ Global Hospital, Mumbai 400012, Maharashtra, India \\ (e-mail: gauravkpatil@gmail.com).
}

\begin{abstract}
\section{Keywords}

- endoscopy

- gastroenterology

- Helicobacter pylori

- community

- outcomes

Background Patients with gastrointestinal ( $\mathrm{Gl}$ ) symptoms in remote areas do not have access to standard medical care with the issues related to cost of medical care, transportation, health literacy, lack of healthcare insurance-all preventing healthcare access in a timely manner. To overcome this, we designed a mobile endoscopy van with the intent to provide free essential medical services to the rural population.

Methods This is a retrospective study of patients with predominantly upper $\mathrm{Gl}$ symptoms at two community health centers (each 2 days camp). This is an audit of endoscopy findings in a community set up using a Mobile Endoscopy Unit (MEU). Patients' details were collected in a pre-designed questionnaire. Only those patients with alarm symptoms and suspicion of any pathological state underwent esophagogastroduodenoscopy (EGD) in MEU. Data analysis was done using descriptive statistics. Results A total of 724 patients (424 [58.5\%] males; mean [SD] age 48.5 [5.2] years) were included. The commonest presenting symptom was heartburn in 377 (52.1\%) patients. The median duration of symptoms was 6.5 (range: $2-36)$ months. Gastroesophageal reflux disease was seen in $16(6.8 \%)$ patients, ulceroproliferative growth was noted in the stomach in $3(1.3 \%)$ patients. Eighteen $(7.6 \%)$ patients had a positive rapid urease test and received Helicobacter pylori eradication therapy. The most commonly prescribed drugs were proton-pump inhibitors in 692 (95.6\%) patients. Nine (1.2\%) patients had chronic liver disease secondary to alcoholism and were counseled for abstinence. All procedures were safely performed without any immediate adverse events.

Conclusions Community outreach strategies such as the use of mobile endoscopy unit were found to be very useful in the diagnosis of $\mathrm{Gl}$ symptoms. More research is needed in low-income countries to treat complex pathological states in rural patients.
\end{abstract}

DOI https://doi.org/ $10.1055 / \mathrm{s}-0041-1741387$. ISSN 0976-5042. (c) 2022. Society of Gastrointestinal Endoscopy of India. All rights reserved.

This is an open access article published by Thieme under the terms of the Creative Commons Attribution-NonDerivative-NonCommercial-License, permitting copying and reproduction so long as the original work is given appropriate credit. Contents may not be used for commercial purposes, or adapted, remixed, transformed or built upon. (https://creativecommons.org/ licenses/by-nc-nd/4.0/)

Thieme Medical and Scientific Publishers Pvt. Ltd., A-12, 2nd Floor, Sector 2, Noida-201301 UP, India 


\section{Introduction}

Healthcare expenditure in India is unaffordable for the majority of the patients. ${ }^{1}$ Due to an increase in the cost of medical care combined with absence or inadequate medical insurance coverage, patients cannot afford to be sick. ${ }^{2}$ As per the World Health Organization (WHO) in 2016, the out-ofpocket expenses for health in India is 65\% versus $20 \%$ across the world. The poor people in India pay more to avail of hospitalization in public health centers. ${ }^{3}$ Patients cannot afford to pay for their medications or are not being reached by public health facilities. ${ }^{4}$ Patients in remote areas do not have access to standard medical care with the issues related to cost of medical care, transportation, health literacy, lack of healthcare insurance-all preventing healthcare access in a timely manner. In today's world, traveling toward the disease and treating it is essential. ${ }^{5}$ The healthcare system in India still struggles with rural doctor shortages. ${ }^{6}$ Meanwhile, functional gastrointestinal (GI) disorders and liver diseases are increasing in rural India. ${ }^{7,8}$ Irregular and unhealthy food habits, bad lifestyle habits, poor sanitation all contribute to an increase in GI ailments. To overcome the various barriers, and treat these patients, we conducted medical camps at two community centers utilizing a mobile endoscopic unit. The impact of new aspects of this modern endoscopy service, its outcomes, and its challenges are discussed.

\section{Methods}

This was a retrospective analysis of prospectively collected data of patients who presented with predominantly upper GI symptoms at two community health centers from January 2020 to October 2020. It is an audit of endoscopy findings in a community set up using a Mobile Endoscopy Unit (MEU). This study was conducted in accordance with Good Clinical Practice and in a manner to conform with the Helsinki Declaration of 1975, as revised in 2013 concerning human rights. This study was approved by the Institutional Ethics Committee (IEC/OA-38/20) and a waiver of informed consent was obtained.

\section{Mobile Endoscopy Unit}

A senior gastroenterologist with the help of a senior endoscopy technician designed a mobile medical unit by providing innovative solutions to render a bus into a custom-made endoscopy unit. The doctors within a MEU can obtain clinical history, examine patients (ergonomically designed examination table), and perform basic diagnostic endoscopic procedures. MEU has one endoscopic suite that meets standards of care for the operating room and two consultation rooms. MEU is fully air-conditioned with requisite power and water on board. It has an in-built generator and can also connect to nearby building infrastructure for power. It has wheelchair lifts for patients with special needs. MEU is integrated with all Medical Gas Systems $\left(\mathrm{O}_{2}\right.$, air, and vacuum), endoscopy equipment storage cabinet, HEPA filtration system, patient monitors, and pharmacy kart (essential medicines). MEU also has adequate space for placing soiled linen, a cleaning area (endoscopic reprocessing), and a lavatory. MEU has adequate light, CCTV, and state-of-the-art equipment integrated for recording and transmission of video signals. All the facilities make it a safe, modern, reliable, and efficient endoscopy mobile unit complying with the medical standards.

\section{Health Screening Camps}

The Government of Maharashtra helped organize medical camps at two community centers. Community center 1 (CC1) (January 28 and 29, 2020) included Thane, Maharashtra, while community center 2 (CC2) (October 30 and 31, 2020) was at Satara, Maharashtra. Patients in the selected locality were already briefed regarding the free gastroenterologyrelated health camp (by advertising in newspapers and other media). The two nearby coordinating centers were Civil Hospital Thane, and Morarji Gokuldas Rural Hospital, Satara, respectively. The doctors of the latter hospital ensured that patients at CC2 had undergone RT-PCR for COVID-19.

All patients had to previously undergo routine laboratory investigations, in addition to an electrocardiogram. The diagnostic indications for upper gastrointestinal endoscopy were met. A subset of patients also had dyspeptic alarm symptoms which needed a standard gastroscopy evaluation. Patients had a detailed clinical examination. Endoscopic procedures were performed under local anesthesia with the patients in the left lateral position. The procedures were done by a senior endoscopist with $>30$ years of experience and two senior gastroenterology fellows with adequate endoscopy training. Only diagnostic endoscopic procedures were performed using the gastroscope (GIF HQ190, Olympus, Japan). During esophagogastroduodenoscopy (EGD), esophagitis (Los Angeles classification scale), flap valve length, circumference, and Hills grade were assessed. ${ }^{9,10}$ Once the diagnosis had been made, doctorprescribed medicines were provided free of cost (-Fig. 1). The presence of any pathological state (gastric malignancy, esophageal varices needing ligation/chronic liver disease) needing further interventions was referred to tertiary care government hospitals to enable patients for free treatment. Endoscope disinfection was done by utilizing both manual and automated methods in the portable SCOPE BUDDYтм PLUS Endoscope Flushing Aid (SBP-1000, Cantel Medical, Canada) for optimal cleaning. Endotech Endosauber-fully automatic endowasher was also available at both the community hospitals for alternate scope cleaning.

We included all patients who attended the health camp for analysis. We excluded those patients who had incomplete details or missing information and symptoms unrelated to gastrointestinal diseases. Demographics of all patients including those undergoing endoscopic procedures were entered into MS Excel (Office 2019 Professional for Windows; Microsoft). The statistical analysis was performed using IBM Statistical Package for the Social Sciences (SPSS) Statistics for Windows [version 23.0, Professional] (IBM Corp., Armonk, N. Y., USA). Categorical variables are reported as frequency and percentages. For continuous variables, descriptive statistics were used. 

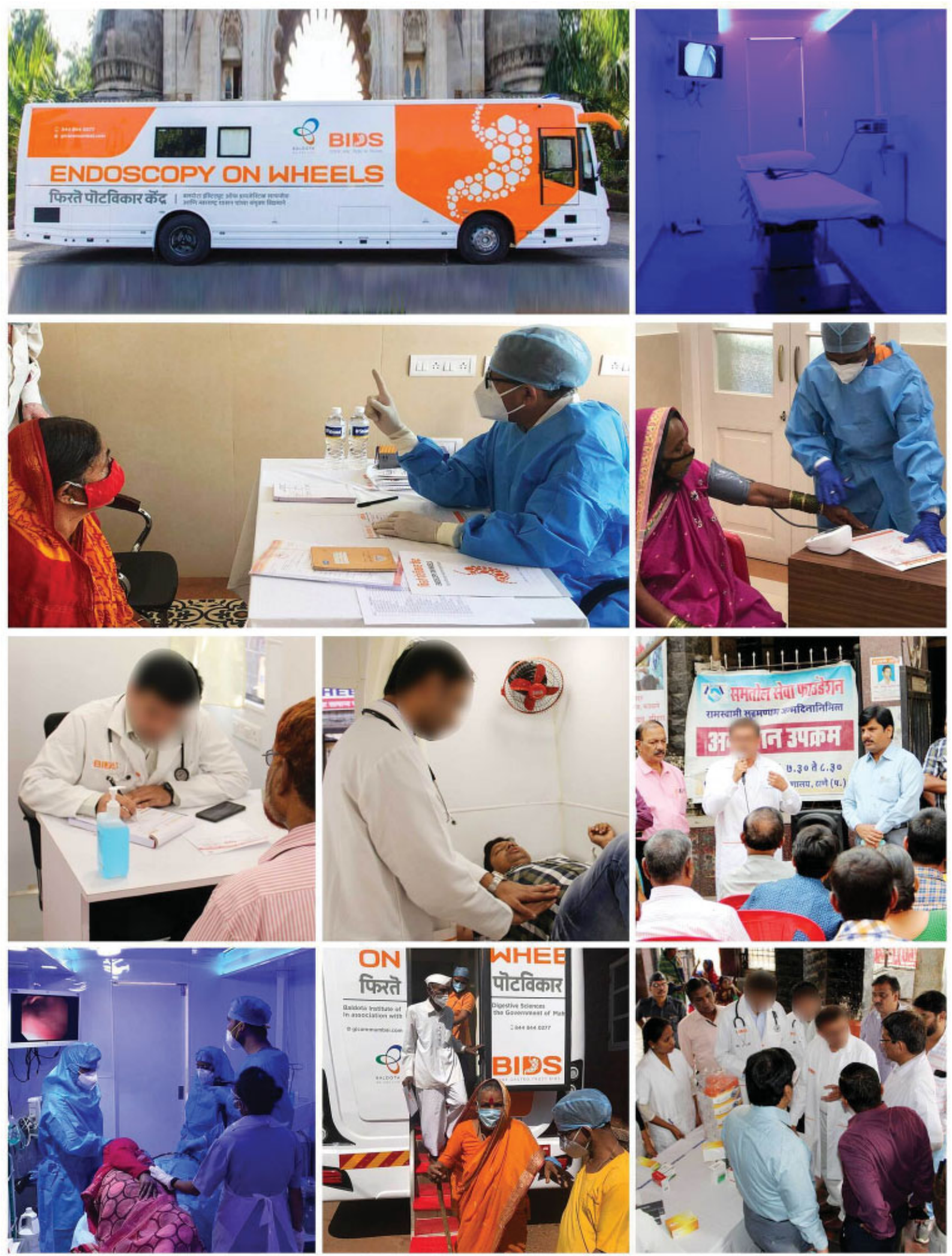

Fig. 1 Doctors providing community services in the mobile endoscopy unit.

\section{Results}

At the two health camps, 729 individuals visited the MEU. Five patients had incomplete details, hence were excluded from the final analysis; therefore, 724 patients were studied. There was male preponderance noted in 424 (58.5\%) patients. Their mean (SD) age was 48.5 (5.2) years. The commonest presenting symptom was heartburn in 377 
Table 1 Demographic characteristics of patients

\begin{tabular}{|l|l|l|}
\hline Patient characteristics & CC1 & CC2 \\
\cline { 2 - 3 } & $N(\%)$ & $N(\%)$ \\
\hline Total no. of patients, $n(\%)$ & $426(100)$ & $298(100)$ \\
\hline Mean (SD) years & $42.4(6.5)$ & $50.1(4.9)$ \\
\hline Male & $221(51.9)$ & $203(68.1)$ \\
\hline M:F & $1.1: 1$ & $2.1: 1$ \\
\hline Diet & & \\
\hline Mixed & $101(23.7)$ & $59(19.8)$ \\
\hline Vegetarian & $325(76.3)$ & $239(80.2)$ \\
\hline BMI, mean (SD), kg/m ${ }^{2}$ & $24.9(1.1)$ & $23.5(1.8)$ \\
\hline $\begin{array}{l}\text { Duration of symptoms, } \\
\text { median (range), (months) }\end{array}$ & $6(2-36)$ & $7(2-30)$ \\
\hline Alcohol & $20(4.7)$ & $12(4)$ \\
\hline Smoking & $18(4.2)$ & $11(3.7)$ \\
\hline Presenting symptoms* & & \\
\hline Heartburn & $259(60.8)$ & $118(39.6)$ \\
\hline Bloating & $115(26.9)$ & $46(15.4)$ \\
\hline Abdominal pain or discomfort & $128(30)$ & $60(20.1)$ \\
\hline Nausea/vomiting & $25(5.9)$ & $20(6.7)$ \\
\hline Extra esophageal symptoms & $5(1.2)$ & $2(0.7)$ \\
\hline $\begin{array}{l}\text { Constipation/defecation } \\
\text { disorder }\end{array}$ & $54(12.7)$ & $45(15.1)$ \\
\hline Ascites & $4(0.9)$ & $2(0.7)$ \\
\hline Anorexia & $29(6.8)$ & $15(5)$ \\
\hline Weight loss & $15(3.5)$ & $9(3)$ \\
\hline Some & & \\
\hline
\end{tabular}

*Some patients may have more than one presenting symptom.

(52.1\%) patients, followed by abdominal pain in 188 (25.9\%) patients ( - Table 1 ). The median duration of symptoms was 6.5 (range: 2-36) months. A total of 724 consultations resulted in the need for minimally invasive EGD in 235 (32.4\%) patients. It was safely performed in all the patients without any immediate adverse events. Gastroesophageal reflux disease (GERD) was seen in $16(6.8 \%)$ patients and laxity of the lower esophageal sphincter in 17 (7.2\%) patients (-Table 2). An ulceroproliferative growth was seen in the stomach in 3 (1.3\%) patients possibly malignant. Biopsies were taken and sent for histopathological examination to nearby centers. These patients were asked to follow up at the nearby tertiary care centers for further treatment. Protonpump inhibitors (PPI) were the most commonly prescribed drugs in 692 (95.6\%) patients (-Table 3). Eighteen (7.6\%) patients had a positive rapid urease test and received Helicobacter pylori eradication therapy for 14 days (PPI, amoxicillin $1 \mathrm{~g}$ and clarithromycin $500 \mathrm{mg}$ each twice daily). All patients were asked to complete the full course of treatment. Eleven (4.7\%) patients had peptic ulcers, out of which five patients had a history of NSAID for osteoarthritis. Nine (1.2\%) patients had chronic liver disease secondary to alcoholism. These patients were counseled for abstinence from alcohol
Table 2 Endoscopic findings of patients

\begin{tabular}{|l|l|l|}
\hline \multirow{2}{*}{$\begin{array}{l}\text { Procedural } \\
\text { details }\end{array}$} & $\mathrm{CC}^{*}$ & $\mathrm{CC}^{*}$ \\
\cline { 2 - 3 } & $\mathrm{N}(\%)$ & $\mathrm{N}(\%)$ \\
\hline $\begin{array}{l}\text { Total no. of patients, } \\
n \text { (\%) }\end{array}$ & $137(100)$ & $98(100)$ \\
\hline Endoscopy diagnosis & & \\
\hline GERD LA A & $5(3.6)$ & $4(4.1)$ \\
\hline GERD LA B & $3(2.2)$ & $2(2)$ \\
\hline GERD LA C & $2(1.4)$ & - \\
\hline laxity (LAX) LES & $11(8)$ & $6(6.1)$ \\
\hline Hiatus hernia & $7(5.1)$ & $5(5.1)$ \\
\hline Esophageal varices & $3(2.2)$ & $2(2)$ \\
\hline Gastric ulcers & $4(2.9)$ & $3(3.1)$ \\
\hline Duodenal ulcers & $2(1.4)$ & $2(2)$ \\
\hline Proliferative growth & $2(1.4)$ & $1(1)$ \\
\hline $\begin{array}{l}\text { Portal hypertensive } \\
\text { gastropathy }\end{array}$ & $3(2.2)$ & $2(2)$ \\
\hline $\begin{array}{l}\text { Gastric antral vascular } \\
\text { ectasia (GAVE) }\end{array}$ & $1(0.7)$ & - \\
\hline $\begin{array}{l}\text { rapid urease test } \\
\text { (RUT)-positive }\end{array}$ & $10(7.3)$ & $8(8.2)$ \\
\hline $\begin{array}{l}\text { Patients referred to } \\
\text { government tertiary } \\
\text { care centers }\end{array}$ & $5(3.6)$ & $4(4.1)$ \\
\hline
\end{tabular}

*Some patients may have more than one diagnosis.

Community center 1 (CC1), Community center 2 (CC2).

and smoking. The patients with identified ulceroproliferative growth and liver diseases were incidentally identified in the camps. Patients who had an indication for colonoscopy were given symptomatic therapy and were referred to the nearby tertiary care center to get a colonoscopy at the earliest.

\section{Discussion}

Health care in rural parts of the world needs adequate medical attention. By retrospectively analyzing patients who visited the two health camps, we studied the usefulness of MEU in day-to-day gastroenterological needs in rural India. The results highlight the need for camp-based screening services at regular intervals in the community. Currently, the program is active across Maharashtra, India. There have been similar attempts done in gynecology and general medicine in rural India and other parts of the world. ${ }^{11,12}$ But super-specialty mobile health camps especially in gastroenterology are explored to a lesser extent. One such health camp was initially successful when introduced in early $2012 ;^{13}$ however, there has been no follow-up of such initiatives.

We found that $43(18.3 \%)$ patients had endoscopic evidence of GI ailments. GERD was seen in 16 (6.8\%) patients and laxity of the lower esophageal sphincter in 17 (7.2\%) patients. Some patients were not ready for the endoscopic procedure; hence, it was not performed and symptomatic 
Table 3 Medications

\begin{tabular}{|l|l|l|}
\hline Medications & $\begin{array}{l}\text { CC1\# } \\
\text { N=426 }\end{array}$ & $\begin{array}{l}\text { CC2\# } \\
\text { N=298 }\end{array}$ \\
\hline $\begin{array}{l}\text { Proton-pump } \\
\text { inhibitors }\end{array}$ & $325(76.3)$ & $224(75.2)$ \\
\hline $\begin{array}{l}\text { Proton pump inhibi- } \\
\text { tors + prokinetics }\end{array}$ & $90(21.1)$ & $53(17.8)$ \\
\hline Digestive enzymes & $35(8.2)$ & $26(8.7)$ \\
\hline $\begin{array}{l}\text { Helicobacter pylori } \\
\text { eradication therapy } \\
\text { (14 days) }\end{array}$ & $10(2.3)$ & $8(2.7)$ \\
\hline Cyproheptadine & $12(2.8)$ & $6(2)$ \\
\hline Multivitamins & $25(5.9)$ & $18(6)$ \\
\hline Rifaximin & $10(2.3)$ & $3(1)$ \\
\hline Drotaverine & $22(5.2)$ & $12(4)$ \\
\hline $\begin{array}{l}\text { Lactitol monohydrate } \\
\text { with ispaghula }\end{array}$ & $54(12.7)$ & $45(15.1)$ \\
\hline
\end{tabular}

*Some patients may have more than one medication. Community center 1 (CC1), Community center 2 (CC2).

treatment was given. The patients were told about lifestyle modifications viz. to avoid lying down immediately after a meal, minimization or avoidance of caffeinated drinks, the head end of the bed to be elevated before sleep and to eat smaller meals. GERD affects the quality of life, contributes to sleep disturbances, and affects eating habits. ${ }^{14}$ These patients are at increased risk of developing esophageal cancer. ${ }^{15}$ Hence, there is a need to identify these individuals and treat them accordingly.

An ulceroproliferative growth was seen in the stomach in three $(1.3 \%)$ patients, which was possibly malignant. The patients' caretakers were briefed regarding the condition and were asked to follow up at a nearby center for further treatment. An emergency medical helpline number of the host institute was provided to them for any urgent queries. Constipation and bloating were other common problems encountered by patients. Patients with constipation were given stool softeners and were asked to do regular physical activities and consume adequate fluids.

The incidence and prevalence of liver disease in India are growing exponentially. We had 9 (1.2\%) patients with chronic liver disease secondary to alcoholism and were counseled for abstinence. Two patients had moderate ascites and were told to undergo paracentesis at a nearby hospital. Eleven (4.7\%) patients had peptic ulcers, out of which five patients had a history of NSAID for osteoarthritis. They were told to avoid over-the-counter analgesic medications and were referred to an orthopedics department of a nearby hospital.

Transportation is a major barrier to health care access, impacting as little as $3 \%$ to as much as $67 \%$ of patients. ${ }^{16-18}$ The initial challenges were time management and the availability of limited resources. Through our analyses in each of these community health camps, we could not put forth some recommendations related to public health in rural India.
However, the majority of the barriers can be easily dealt with community-based camps utilizing MEU. We presume the usefulness seen through such camps might bring in policy changes that may help patients in rural districts. The study does have its limitations. This was a descriptive study, findings of which are not generalizable outside this environment. Although not likely, selection bias might be present. But, because it was a cross-sectional study with a noncomparative design, it may not have influenced any outcomes. We did not do a follow-up to see if our camp has led to improved health and health behaviors among these patients. However, such community health camps have helped improve access to and use of essential medical services. $^{19,20}$

To summarize, the gastroenterology ailment-related health camps conducted at two prime community centers with the use of MEU were found to be very useful in the diagnosis of GI symptoms. The success of this camp was seen through effective community consultation and good patient participation. There is a need for more research in low- to middle-income countries including India to treat rural patients so that the epidemiology of GI ailments is studied and remains low.

\section{Statement of Ethics}

Given the cross-sectional nature of the study, the Institutional Ethics Committee waived the written informed consent. The principles of the Declaration of Helsinki were respected throughout the study. The study protocol had been approved by the Institutional Ethics Committee.

\section{Authors' Contributions}

NK, SV, and AM: study concept and design. AD, GP, AV, ST, and AM: clinical management of all cases. NK, SV, and ST: data acquisition. NK: prepared the first draft of the manuscript. AD, GP, and AM: critical revision and provided vital inputs. All the authors reviewed and approved the final version of the manuscript.

Funding

None.

\section{Conflicts of Interest}

None declared.

\section{Acknowledgments}

Our ability to do this camp is positively influenced by the incredible support and generosity of our donors, especially from Shri. Narendrakumar A. Baldota and his family. The mobile endoscopy van was also sponsored by the Baldota Group (Hosapete, Karnataka, India). We would also like to thank the Government of Maharashtra for helping to organize medical camps. A sincere thanks to the technicians and nursing staff for their continuous support, as well the patients who have benefited from this camp. We are grateful to Mr. Milind Jadhav for editing the pictures. 


\section{References}

1 Selvaraj S, Farooqui HH, Karan A. Quantifying the financial burden of households' out-of-pocket payments on medicines in India: a repeated cross-sectional analysis of National Sample Survey data, 1994-2014. BMJ Open 2018;8(05):e018020

2 Kastor A, Mohanty SK. Disease-specific out-of-pocket and catastrophic health expenditure on hospitalization in India: do Indian households face distress health financing? PLoS One 2018;13(05):e0196106

3 Dash A, Mohanty SK. Do poor people in the poorer states pay more for healthcare in India? BMC Public Health 2019;19(01):1020

4 Bhaumik S, Biswas T. Free medicine for all in India. CMAJ 2012; 184(15):E783-E784

5 Syed ST, Gerber BS, Sharp LK. Traveling towards disease: transportation barriers to health care access. J Community Health 2013;38(05):976-993

6 Sharma DC. India still struggles with rural doctor shortages. Lancet 2015;386(10011):2381-2382

7 Ghoshal UC, Singh R. Frequency and risk factors of functional gastro-intestinal disorders in a rural Indian population. J Gastroenterol Hepatol 2017;32(02):378-387

8 Shah D, Makharia GK, Ghoshal UC, Varma S, Ahuja V, Hutfless S. Burden of gastrointestinal and liver diseases in India, 1990-2016. Indian J Gastroenterol 2018;37(05):439-445

9 Jobe BA, Kahrilas PJ, Vernon AH, et al. Endoscopic appraisal of the gastroesophageal valve after antireflux surgery. Am J Gastroenterol 2004;99(02):233-243

10 Hill LD, Kozarek RA, Kraemer SJ, et al. The gastroesophageal flap valve: in vitro and in vivo observations. Gastrointest Endosc 1996;44(05): 541-547

11 Edgerley LP, El-Sayed YY, Druzin ML, Kiernan M, Daniels KI. Use of a community mobile health van to increase early access to prenatal care. Matern Child Health J 2007;11(03):235-239
12 Yu SWY, Hill C, Ricks ML, Bennet J, Oriol NE. The scope and impact of mobile health clinics in the United States: a literature review. Int J Equity Health 2017;16(01):178

13 Talukdar R, Reddy DN. Making endoscopy mobile: a novel initiative for public healthcare. Endoscopy 2012;44(02): 186-189

14 Lee SW, Lien HC, Lee TY, Yang SS, Yeh HJ, Chang CS. Heartburn and regurgitation have different impacts on life quality of patients with gastroesophageal reflux disease. World J Gastroenterol 2014;20(34):12277-12282

15 Herbella FA, Neto SP, Santoro IL, Figueiredo LC. Gastroesophageal reflux disease and non-esophageal cancer. World J Gastroenterol 2015;21(03):815-819

16 Bambra C, Gibson M, Sowden A, Wright K, Whitehead M, Petticrew M. Tackling the wider social determinants of health and health inequalities: evidence from systematic reviews. J Epidemiol Community Health 2010;64(04):284-291

17 Guidry JJ, Aday LA, Zhang D, Winn RJ. Transportation as a barrier to cancer treatment. Cancer Pract 1997;5(06):361-366

18 Zullig LL, Jackson GL, Provenzale D, Griffin JM, Phelan S, van Ryn M. Transportation: a vehicle or roadblock to cancer care for VA patients with colorectal cancer? Clin Colorectal Cancer 2012;11 (01):60-65

19 Woldie M, Feyissa GT, Admasu B, et al. Community health volunteers could help improve access to and use of essential health services by communities in LMICs: an umbrella review. Health Policy Plan 2018;33(10):1128-1143

20 Cyril S, Smith BJ, Possamai-Inesedy A, Renzaho AM. Exploring the role of community engagement in improving the health of disadvantaged populations: a systematic review. Glob Health Action 2015;8:29842 